\title{
Protein Digestion and Quality of Goat and Cow Milk Infant Formula and Human Milk Under Simulated Infant Conditions
}

\author{
${ }^{*}$ Annet Maathuis, ${ }^{*}$ Robert Havenaar, ${ }^{\dagger}$ Tao He, and ${ }^{*}$ Susann Bellmann
}

\begin{abstract}
Objective: The aim of this study was to determine the kinetics of true ileal protein digestion and digestible indispensable amino acid score (DIAAS) of a goat milk-based infant formula (GIF), a cow milk-based infant formula (CIF), and human milk (HM).

Methods: The GIF, CIF, and HM were investigated in an in vitro gastrointestinal model simulating infant conditions. Digested compounds were dialyzed from the intestinal compartment as bioaccessible fraction. Dialysate was collected in 15 to 60-minute periods for 4 hours. True ileal protein digestibility and DIAAS were determined as bioaccessible nitrogen $(\mathrm{N})$ and amino acids.

Results: N bioaccessibility from the GIF showed similar kinetics to that of HM. The CIF showed a delay in N bioaccessibility versus the GIF and HM. In the 1st hour of digestion, $\mathrm{N}$ bioaccessibility was $19.9 \% \pm 3.5 \%$ and $23.3 \% \pm 1.3 \%$ for the GIF and HM, respectively, and $11.2 \% \pm 0.6 \%$ for CIF ( $P<0.05$ vs HM). In the 3 rd hour of digestion, the N bioaccessibility was higher $(P<0.05)$ for the CIF $(28.9 \% \pm 1.2 \%)$ than for the GIF $(22.5 \% \pm 1.6 \%)$ and $\mathrm{HM}(20.6 \% \pm 1.0 \%)$. After 4 hours, the true ileal protein digestibility of the GIF, CIF, and HM was $78.3 \% \pm 3.7 \%, 73.4 \% \pm 2.7 \%$, and $77.9 \% \pm 4.1 \%$, respectively. The DIAAS for the GIF, CIF, and HM for 0 - to 6-month-old infants was $83 \%, 75 \%$, and $77 \%$ for aromatic AA.

Conclusion: The protein quality is not different between the GIF, CIF, and $\mathrm{HM}$, but the kinetics of protein digestion of the GIF is more comparable to that of HM than that of the CIF.
\end{abstract}

Key Words: DIAAS, digestible indispensable amino acid score, protein digestion kinetics, true ileal protein digestibility

(JPGN 2017;65: 661-666)

Received June 8, 2017; accepted September 4, 2017

From *Triskelion B.V., Zeist, and †Ausnutria Hyproca B.V., Zwolle, The Netherlands.

Address correspondence and reprint requests to Annet Maathuis, BSc, Triskelion B.V. Utrechtseweg 48, 3704 HE Zeist, The Netherlands (e-mail: annet.maathuis@triskelion.nl).

Financial disclosure statement: Ausnutria-Hyproca B.V. sponsored research and delivery of infant formulas; Triskelion conducted the research. All authors declare no financial disclosures.

T.H. is an employee of Ausnutria Hyproca B.V., the founding sponsor of this study. R.H., S.B., and A.M. are employees of Triskelion B.V. and conducted the research. All authors contributed to the manuscript.

The authors report no conflicts of interest.

Copyright $(02017$ The Author(s). Published by Wolters Kluwer Health, Inc. on behalf of the European Society for Pediatric Gastroenterology, Hepatology, and Nutrition and the North American Society for Pediatric Gastroenterology, Hepatology, and Nutrition. This is an open access article distributed under the terms of the Creative Commons AttributionNon Commercial-No Derivatives License 4.0 (CCBY-NC-ND), where it is permissible to download and share the work provided it is properly cited. The work cannot be changed in any way or used commercially without permission from the journal.

DOI: 10.1097/MPG.0000000000001740

\section{What Is Known}

- Growth of infants feeding goat or cow milk infant formula is not different.

- Goat, cow, and human milk differ in caseins.

\section{What Is New}

- True ileal protein digestibility of goat and cow milk infant formula is similar to that of human milk.

- Protein digestion of cow milk infant formula is delayed compared to goat milk infant formula and human milk.

- Digestible indispensable amino acid score can be determined in in vitro dynamic models simulating infant digestion.

- Digestible indispensable amino acid score of goat and cow milk infant formula for infants is not different compared to human milk.

W hen breast-feeding is not sufficient or not possible, it is important to have high quality infant formulas available. Traditionally infant formula (IF) is based on cow milk proteins with an adapted ratio of casein to whey proteins by the addition of whey proteins. Nevertheless, there is an increasing consumer demand for goat milk-based IF (GIF). It has been shown that GIF provided growth and nutritional outcomes in infants similar to that of standard whey-dominant cow milk-based IF (CIF) $(1,2)$. The knowledge, however, about protein digestion and availability for absorption of indispensable amino acids (IAAs) from IFs for infants is not yet completed. The Food and Agriculture Organization (FAO) (3) recommends to evaluate the protein quality based on true protein digestibility in the small intestine and the bioavailability of individual IAA. This should be used to calculate the Digestible Indispensable Amino Acid Score (DIAAS), which is the first limiting IAA as ratio of the IAA requirement for different age groups, for example, infants. The true IAA bioavailability should preferably be determined in humans (3). Digestion experiments in infants, however, have clinical and ethical drawbacks. Digestion experiments in young piglets as previously described $(4,5)$ also have ethical constrains. An option is to use ex vivo gastrointestinal enzymes in static models $(6,7)$. A better alternative might be the use of dynamic in vitro gastrointestinal models simulating infant digestion conditions $(8,9)$. In the present study 
we used a dynamic in vitro gastrointestinal model (tiny-TIM) as described previously $(10,11)$, improved with a 3-stage gastric compartment (12). This model has been validated for simulating the conditions in the upper gastrointestinal tract of neonates, infants, and toddlers (13), for studying the true ileal protein digestibility with an in vitro-in vivo correlation coefficient of $0.94(10,11,14)$ and determining the in vitro DIAAS $(11)$. Knowledge about IAA bioavailability of goat milk products is limited, but important for understanding GIFs. The aim of this study is to compare the kinetics of true ileal protein and AA digestibility and DIAAS of a GIF, a CIF, and HM in tiny-TIM under simulation of infant digestive conditions.

\section{METHODS}

\section{Products}

In this study, we used a GIF and CIF manufactured under similar GMP processing by Ausnutria Hyproca (Zwolle, Netherlands), and HM pooled from 6 volunteers. The GIF and CIF were whey protein enhanced to a whey:casein ratio of 60:40. After signing an informed consent, HM was collected 3 to 5 months postpartum. To collect sufficient HM, it was necessary to freeze and store $\mathrm{HM}$ at $-80^{\circ} \mathrm{C}$. In daily practice, $\mathrm{HM}$ is also often stored under frozen conditions before use. HM was used in the experiments within 2 to 3 months after collection, after overnight thawing at $6^{\circ} \mathrm{C}$.
The GIF (16.9 g) and CIF (18.9 g) powders were suspended in $112.5 \mathrm{~mL}$ water. For GIF, this was according to the label instruction; for CIF, it was $2 \mathrm{~g}$ higher than the label instruction to standardize the amount of protein intake at $2.1 \mathrm{~g}$ per experiment. The analyzed concentration of nitrogen $(\mathrm{N})$ and AA in the reconstituted IFs and in the pooled HM (Table 1) was used to calculate the actual amount of protein and AA intake in the experiments.

\section{Gastrointestinal Model}

The experiments were performed in a dynamic gastrointestinal model (tiny-TIM) as described and validated for protein digestion previously $(10,11,13,14)$. The model consists of a gastric compartment with a fundus and antrum function (12), a pyloric valve, and a small intestinal compartment. The food is mixed with added digestive enzymes, electrolytes, and bile by peristaltic movements of a flexible wall. The gastric content is gradually emptied into the small intestine via the pyloric valve. All settings are computer-controlled related to the age group to be simulated and the type of food. For dialysis of the digested products and for water absorption, a cartridge with hollow-fiber semi-permeable membranes (Sureflux-07L Hemodialyzer; Nipro, Belgium) was connected to the intestinal compartment. Dialysate was pumped through the hollow fibers at $10 \mathrm{~mL} / \mathrm{min}$. The dialyzed nutrients

TABLE 1. Analyzed concentration of nitrogen, indispensable amino acids (IAA) and dispensable amino acids (DAA) of reconstituted goat milk and cow milk based infant formula (IF) and human milk

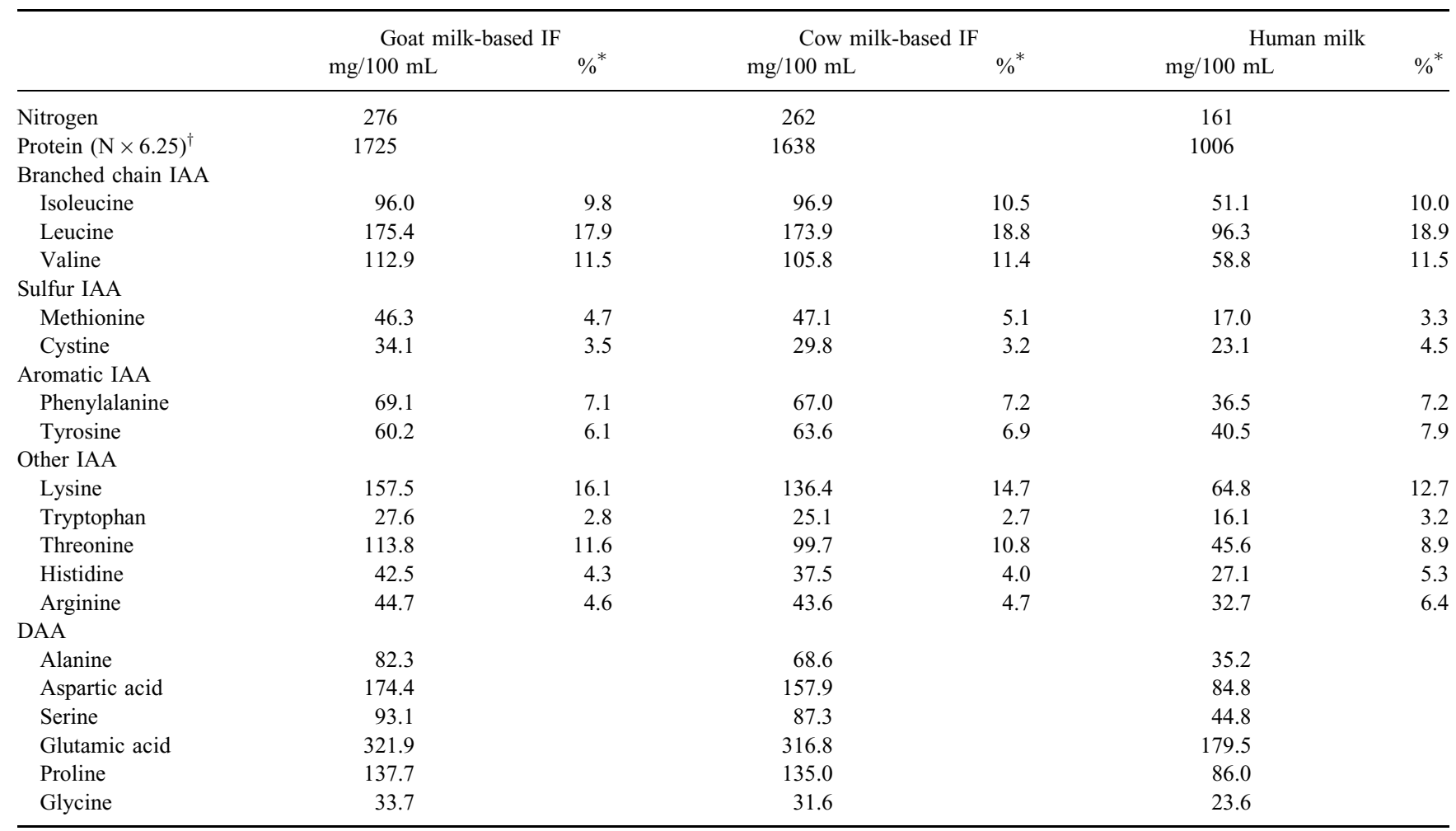

$\mathrm{DAA}=$ dispensable amino acid; $\mathrm{IAA}=$ indispensable amino acid; $\mathrm{IF}=$ infant formula

${ }^{*}$ Calculated as percentage of total IAA.

${ }^{\dagger}$ Not corrected for non-protein nitrogen. 
represent the compounds that are available for intestinal absorption (bioaccessible fraction) after digestion, such as small peptides and AA.

\section{Simulated Infant Gastrointestinal Conditions}

The test products were investigated in tiny-TIM simulating the conditions in the stomach and small intestine of healthy infants, 1 to 6 months of age, after the intake of IF (13). For this study, the following settings were used: gastric $\mathrm{pH}$-curve from $\mathrm{pH} 6.7$ to 4.8 from 0 to 30 minutes, to $\mathrm{pH} 3.8$ from 30 to 60 minutes, and to $\mathrm{pH} 3.2$ from 60 to 120 minutes, up to the end of the experiment by the addition of $1 \mathrm{~mol} / \mathrm{L} \mathrm{HCl}$; gastric emptying curve with a halftime of 60 minutes and $\beta$-value of 1.5 (determines the s-shape of the emptying curve); intestinal $\mathrm{pH}$ at $6.5 \pm 0.3$ with $1 \mathrm{~mol} / \mathrm{L}$ sodium bicarbonate.

\section{Set-up of the In vitro Digestion Experiments}

Each product and the blank were tested in duplicate for 4 hours (based on 3-4hour feeding periods of infants). Blank experiments were performed to estimate the amount and digestibility of endogenous protein (enzyme and nonenzyme proteins from the pancreatin and bile). These blank experiments were performed with the intake of $118 \mathrm{~g}$ of water, $17 \mathrm{~g}$ of artificial saliva, and $12 \mathrm{~g}$ of citrate buffer.

\section{Visual Observations}

The gastric and intestinal walls of the compartments of the TIM systems are transparent, which enables visual observations during the digestion experiments. Every 10 minutes during the first hour of the experiments, the content in the gastric compartment was monitored and digital pictures were frequently made.

\section{Sampling}

During the experiments, dialysate samples were collected in 15- to 60-minute periods for 4 hours as follows: 0 to 15 minutes, 15 to 30 minutes, 30 to 45 minutes, 45 to 60 minutes, 60 to 90 minutes, 90 to 120 minutes, 120 to 180 minutes, and 180 to 240 minutes. The collected volume per period was measured and 3 subsamples of $30 \mathrm{~mL}$ were stored at $-18^{\circ} \mathrm{C}$ for analysis.

\section{Chemical Analysis}

All collected dialysate samples from the duplicate tiny-TIM experiments were analyzed for total $\mathrm{N}$ (Kjeldahl) and $\alpha$-amino nitrogen (AAN) (to calculate $\mathrm{NH}_{2}$-ending protein fragments). For AA analysis, the dialysate samples were pooled ( $0-4$ hours). The Kjeldahl, AAN, and AA analysis were performed as described previously (11).

\section{Data Analysis}

The mean ( \pm standard deviation; $\mathrm{n}=2$ ) bioaccessible amount of $\mathrm{N}$ and $\mathrm{AA}$ (dialyzed from the intestinal compartment) was calculated as absolute amount (volume $\mathrm{x}$ concentration). By subtracting the mean amount of $\mathrm{N}$ in the dialysate samples of the blank experiments (endogenous $\mathrm{N}$ ) from that in the product samples (endogenous + exogenous $\mathrm{N}$ ), the bioaccessible amount of exogenous $\mathrm{N}$ from the IF and HM was obtained for calculating the true ileal protein and AA digestibility as percentage of exogenous $\mathrm{N}$ or amino acid intake according to equation 1 (11):

$$
\text { True ileal digestibility }[\%]=\frac{(\Sigma) \text { sample }[\mathrm{mg}]-(\Sigma) \text { blank }[\mathrm{mg}]}{\text { Intake }_{(\text {nitrogen or amino acid }[\mathrm{mg}])}} \times 100
$$

The digestible IAA reference ratio of the IF and HM was calculated as described by the FAO (3) with equation 2 :

DIAA reference ratio $=$
$\frac{\text { digestible indispensable amino acid }[\mathrm{mg}] \text { in } 1 \mathrm{~g} \text { test protein }}{\text { digestible indispensable amino acid }[\mathrm{mg}] \text { in } 1 \mathrm{~g} \text { reference protein }}$

The reference IAA scoring pattern for the DIAAS calculation for infants ( $0-6$ months of age) is based on the IAA composition of HM. The DIAAS is the lowest calculated value of the DIAA reference ratio, expressed as percentage (3).

Differences in true ileal protein and AA digestibility between GIF, CIF, and HM were statistically analyzed using analysis of variance followed by $t$ tests using Tukey multiple comparisons test. Values were considered significantly different if $P<0.05$.

\section{RESULTS}

\section{Composition of Products}

The analyzed $\mathrm{N}$ and $\mathrm{AA}$ composition of the reconstituted GIF and CIF were comparable. The measured $\mathrm{N}$ and calculated protein levels of HM were lower than those of the 2 reconstituted IFs (Table 1). The analyzed mean intake of $\mathrm{N}$ for the GIF, CIF, and HM was $340 \pm 1 \mathrm{mg}, 323 \pm 1 \mathrm{mg}$, and $207 \pm 1 \mathrm{mg}$, respectively. The total amount of $\mathrm{N}$ in the samples from the duplicate blank experiments was $280 \pm 1 \mathrm{mg}$.

\section{Visual Characteristics in the Gastric Compartment}

Visual inspection of the milk products in the gastric compartment showed that for the CIF, the protein coagulation to particles was visible between 10 to 60 minutes after the start of the experiment. For the GIF, coagulation was visible around 10 to 30 minutes and for $\mathrm{HM}$ around 10 to 20 minutes.

\section{True Ileal Digestibility and Digestion Kinetics of Proteins}

The true ileal digestibility of the milk products, measured as amount of exogenous $\mathrm{N}$ in the dialysate collected per 15-, 30-, or 60 -minute periods, is shown in Figure 1. The amount of bioaccessible exogenous $\mathrm{N}$ during the digestion of the GIF showed a similar kinetic profile as HM. In the first hour of digestion, the bioaccessible amount of $\mathrm{N}$ was $19.9 \% \pm 3.5 \%$ and $23.3 \% \pm 1.3 \%$ of $\mathrm{N}$ intake for the GIF and HM, respectively. The CIF showed a delay in the bioaccessible amount of $\mathrm{N}$ in the first hour of digestion: $11.2 \% \pm 0.5 \%(P>0.05$ vs GIF; $P<0.05$ vs HM $)$ of intake. In the third hour of digestion, however, the bioaccessible amount of $\mathrm{N}$ was higher $(P<0.05)$ for the CIF $(28.9 \% \pm 1.2 \%)$ in comparison to the GIF $(22.5 \% \pm 1.6 \%)$ and HM $(20.6 \% \pm 1.0 \%)$.

The true ileal protein digestibility after 4 hours of digestion, expressed as percentage of $\mathrm{N}$ intake, showed no significant differences among the 3 test products: GIF $78.3 \% \pm 3.7 \%$, CIF $73.4 \% \pm 2.7 \%$, and $\mathrm{HM} 77.9 \% \pm 4.1 \%$.

The amounts of AAN expressed per gram $\mathrm{N}$ intake for each 1 -h period is given in Figure 1. It shows the same pattern as the 

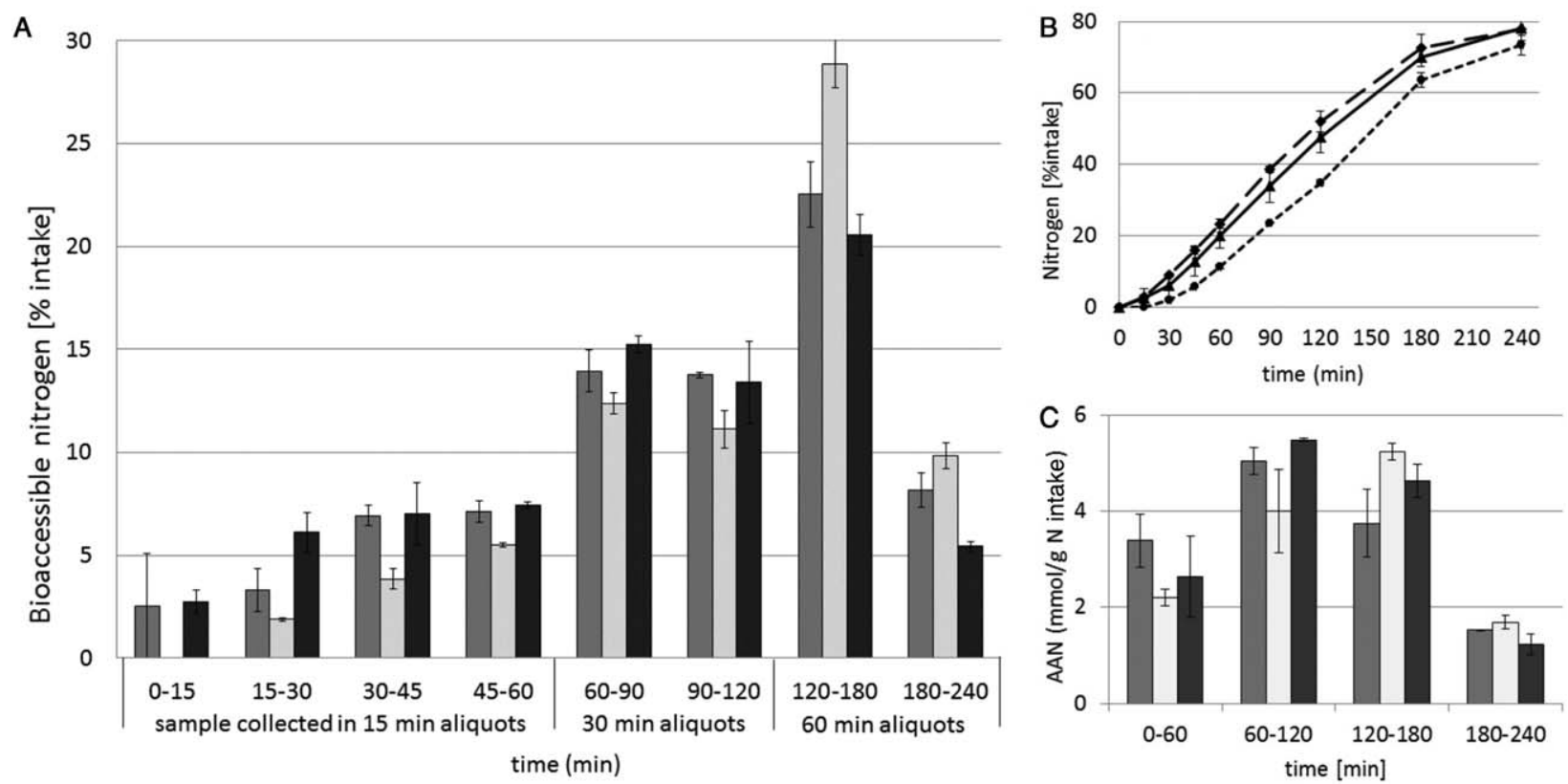

FIGURE 1. (A) Mean ( \pm standard deviation; $n=2$ ) true ileal bioaccessible amount of nitrogen, expressed as percentage of intake, in dialysate samples collected at 15-, 30-, or 60-minute periods for 4 hours of digestion of goat milk infant formula (gray bars), cow milk infant formula (white bars), and human milk (black bars) in tiny-TIM under simulation of infant digestive conditions (1-6 months of age). (B) Mean cumulative bioaccessible amount of nitrogen during digestion of goat milk infant formula (solid line), cow milk IF (dotted line), and human milk (dashed line). (C) Mean bioaccessible amount of $\alpha$-amino nitrogen (AAN) per gram nitrogen intake during digestion of goat milk infant formula (gray bars), cow milk infant formula (white bars), and human milk (black bars).

bioaccessible $\mathrm{N}$ with lower amounts for CIF during the first 2 hours and higher amounts in the 3rd and 4th hour after intake in comparison to GIF and HM. The total values for AAN after 4 hours of digestion were $13.7,13.1$ and $14.0 \mathrm{mmol} / \mathrm{g} \mathrm{N}$ for the GIF, CIF, and HM, respectively.

\section{True Ileal Digestibility of Indispensable Amino Acids and Digestible Indispensable Amino Acid Score}

The concentrations of all AAs $(\mathrm{mg} / 100 \mathrm{~mL}$ product) in the reconstituted GIF and CIF and HM are given in Table 1. Based on the protein content in the milk products (corrected for non-protein $\mathrm{N}$ ) and the data for the bioaccessible IAA in the 0- to 4-hour pooled dialysate samples, the true ileal digestibility of the IAA was calculated per gram of protein intake (Fig. 2). The DIAA reference ratio of each IAA for infants of 0 to 6 months of age is shown in Figure 3. The in vitro DIAAS for infants of the GIF, CIF, and HM, measured after 4 hours of digestion, was $83 \%, 75 \%$, and $77 \%$, respectively, with aromatic AA as first limiting AA for all 3 products. Protein quality with a DIAAS between $75 \%$ and $99 \%$ is regarded as "good" (3).

\section{DISCUSSION}

For determining the protein quality in human nutrition, the FAO recommends to determine the DIAAS, based on the true ileal protein and AA digestibility, preferably performed in humans (3). A suitable alternative is the use of in vitro dynamic, multicompartmental gastrointestinal models simulating as optimal as possible the conditions in the upper gastrointestinal tract of infants. For simulation of infant conditions in tiny-TIM, 3 different settings were developed to simulate the most pronounced maturation stages of the gastrointestinal tract during the first period of life: neonates, infants, and toddlers, respectively, 0 to 1,1 to 6 , and 6 to 24 months of age (13). The FAO references have one age group for infants of 0 to 6 months of age. In the tiny-TIM experiments, the settings of 1 - to 6 month-old infants were used, based on a range of physiological data $(15,16)$ and corresponding with in vitro digestion of IF $(17)$. In combination with previous validation experiments in tiny-TIM $(9-11,14)$, we believe it gives reliable true ileal protein digestion data. To determine true ileal digestibility, the bioaccessibility of endogenous $\mathrm{N}$ was subtracted from that of the total $\mathrm{N}$ per time

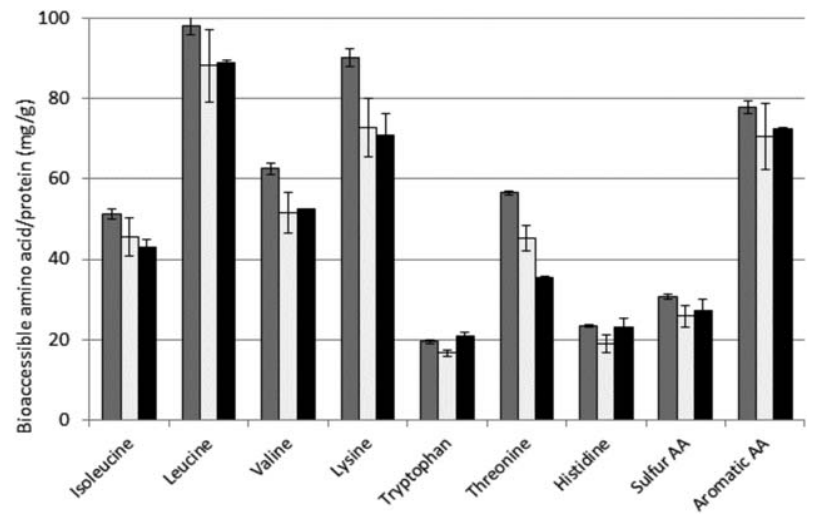

FIGURE 2. Mean ( \pm standard deviation; $n=2$ ) true ileal bioaccessible amount of indispensable amino acids per gram protein (corrected for non-protein nitrogen) calculated for goat milk infant formula (dark grey bars), cow milk infant formula (light grey bars), and human milk (black bars) in tiny-TIM under simulation of infant digestive conditions (1-6 months of age). 


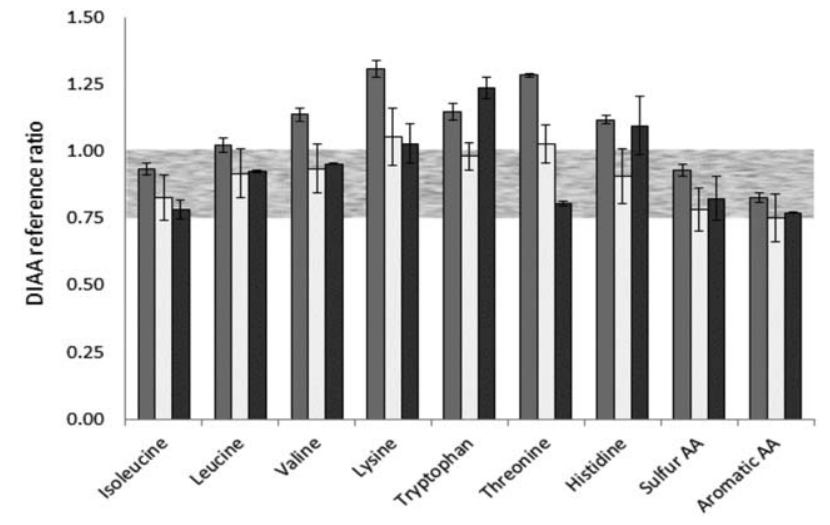

FIGURE 3. Mean ( \pm standard deviation; $n=2$ ) DIAA reference ratio after 4 hours of digestion under simulated infant conditions of goat milk infant formula (dark gray bars), cow milk infant formula (light gray bars), and human milk (black bars). A DIAA reference ratio of 0.75 to 0.99 (grey area) is regarded as "good" and 1.00 or greater as "high" (3). DIAA = digestible indispensable amino acid.

period (Eq.1). Owing to lack of exogenous proteins in the blank experiments, the digestibility of endogenous proteins might be overestimated, resulting in a (slight) underestimation of the exogenous protein bioaccessibility (whereas in fistulated pig studies it might result in overestimation). This is, however, the best possible approach and results show a correlation coefficient of 0.94 with human studies for true ileal protein digestibility (11).

The analyzed concentrations of IAA in the GIF, CIF, and HM show good similarity with the IAA composition, expressed as percentage of total IAA, of GIF and HM as previously reported $(18,19)$. The lysine concentration, however, was $\approx 10 \%$ lower in our $\mathrm{HM}$, probably because of instability during freezing at $-80^{\circ} \mathrm{C}$. Silvestre et al (20) found a decrease in lysine concentration of $\approx$ $35 \%$ after storage at $-20^{\circ} \mathrm{C}$ for 15 days. The intake of exogenous $\mathrm{N}$ for the GIF (340 mg) and CIF (323 mg) was standardized based on the given protein concentration in the milk powder. Standardization at the same amount of $\mathrm{N}$ intake for the HM $(207 \mathrm{mg})$ was not possible, owing to the maximum volume of intake $(130 \mathrm{~mL})$. Based on the $\mathrm{N}$ intake, we intended to calculate the protein intake, which is necessary for the DIAAS calculation. This is, however, not straightforward, because of differences in the $\mathrm{N}$ conversion factor for the various whey proteins, caseins, and other proteins as reported by an ESPGHAN Coordinated International Expert Group (21) and the differences in the amount of non-protein N (NPN) among goat, cow, and human milk $(21,22)$ as well as the method of IF production $(23)$.

Using recommendations and literature data (21-23) for the calculation of protein intake (including free AA) in our experiments, we corrected for $12 \%, 6 \%$, and $20 \%$ non-amino acid nitrogen in the GIF, CIF, and HM, respectively, multiplied with the $\mathrm{N}$ conversion factor of 6.25 . So, the protein intake was $1.87,1.89$, and $1.03 \mathrm{~g}$ for GIF, CIF, and HM, respectively.

The mean total amount of endogenous protein from the secretion fluids was $1.6 \pm 0.1 \mathrm{~g}$ (total $\mathrm{N}$ minus $8 \%$ as estimated $\mathrm{NPN} \times 6.25)$, which is comparable to published in vivo data (24).

In the present study, the 4-hour true ileal protein digestibility of the GIF, CIF, and HM is $78.3 \%, 73.4 \%$, and $77.9 \%$, respectively. The protein digestibility of the CIF tends to be 5\% lower in comparison to the GIF and HM $(P>0.05)$. The true ileal AA digestibility of the GIF was approximately 5\% higher for all IAA in comparison to the CIF, corresponding with the higher true ileal protein digestibility.
In comparison to HM and the GIF, the protein digestion of the CIF was slower in the first hour, but faster in the third hour of digestion. Similar to HM, the bioaccessible N from the GIF could already be detected within 15 minutes after intake. It can be discussed whether this is related to differences in composition of the proteins with consequences for the physicochemical reactions in the gastrointestinal tract. Differences in protein composition between goat and cow milk and HM are reported. For instance, goat milk contains more $\beta$-casein and less $\alpha_{\mathrm{S} 1}$-casein than cow milk, whereas $\beta$-casein is the major protein in $\mathrm{HM}$ in the absence of $\alpha_{\mathrm{S} 1}$-casein $(6,25,26)$. A possible effect can be a difference in clotting behavior of casein in the stomach. The coagulates may consequently cause differences in gastric emptying of the protein because particles larger than a few millimeters will not easily pass the pyloric sphincter, in vivo as well as in tiny-TIM $(27,28)$. Particles of clotted casein have to be broken down by pepsin before gastric emptying. Visual observation of the milk in the gastric compartment showed more persistent particles for the CIF compared to the GIF. For $\mathrm{HM}$, less particles were visible for a shorter time period during gastric passage. Whether this shorter period of coagulation of the GIF versus CIF may influence gut physiology of infants needs further investigation. It has been suggested that in comparison to cow milk, goat milk forms softer and smaller curds in the stomach, which may facilitate digestive actions of the gastric proteases (26). Another possible reason for early appearance of bioaccessible $\mathrm{N}$ in $\mathrm{HM}$ can be the differences in NPN content. As discussed above, HM contains a higher amount of NPN $(20 \%-25 \%)$ than goat milk (15\%) and cow milk $(7 \%)$. This NPN fraction contains mainly free AA, urea, uric acid, and creatin (25). These compounds deliver relatively easily bioaccessible N. The appearance of bioaccessible AAN, however, shows a similar pattern as that of bioaccessible $\mathrm{N}$, that is, higher amounts in the first 2 hours and lower amounts in the last 2 hours of digestion for HM and the GIF in comparison to the CIF. Therefore, the early appearance of bioaccessible $\mathrm{N}$ from HM and GIF might not come from the free AA, but from a faster digestion of the protein.

The bioaccessibility of the individual IAA per gram protein shows small differences between the CIF and HM, whereas the GIF showed somewhat higher levels for most IAA.

The DIAAS for the GIF, CIF, and HM as determined for 0- to 6 -month-old infants was $83 \%, 75 \%$, and $77 \%$ for the aromatic AA when the protein intake was corrected for the nonamino acid nitrogen in the test products as discussed above. The FAO calculates with $25 \% \mathrm{NPN}$ for HM (3), so, not corrected for free AA, resulting in a DIAAS for HM of $82 \%$.

In the present study, the true ileal protein digestibility and DIAAS of the GIF and CIF are similar to those of HM. It can be concluded that the protein quality of the GIF and CIF, under simulated infant digestive conditions, is comparable to that of HM. The CIF shows a slower initial protein digestion in comparison to the GIF and HM. The underlying mechanisms can be investigated in future studies and whether 3 differences may have physiological consequences in infants after ingestion of IF.

Based on the accurate dynamic simulation of infant digestive conditions and the in vitro-in vivo correlation of protein digestion, we expect that the found DIAAS is reliable for infants. Owing to a lack of infant studies (because of ethical constraints), however, with intrinsically labeled proteins, a direct comparison of true AA digestibility in tiny-TIM (as well as in pigs) versus infants is not possible. Further discussions are necessary to evaluate whether dynamic gastrointestinal models are the best possible approach to determine protein quality for adults and infants given the restrictions of in vivo studies. 
Acknowledgment: The authors thank Mark Jelier for the performance of the tiny-TIM experiments and Henrike Wemekamp for carefully reading the manuscript. The study was funded by Triskelion and Ausnutria Hyproca.

\section{REFERENCES}

1. Zhou SJ, Sullivan T, Gibson RA, et al. Nutritional adequacy of goat milk infant formulas for term infants: a double blind randomized controlled trial. Br J Nutr 2014;111:1641-51.

2. Xu M, Wang Y, Dai Z, et al. Comparison of growth and nutritional status in infants receiving goat milk-based formula and cow milk-based formula: a randomized, double blind study. Food Nutr Res 2015;59: 28613.

3. Food and Agriculture Organization (FAO). Dietary protein quality evaluation in human nutrition. FAO Expert Consultation. FAO Food and Nutrition Paper no. 92. Rome: FAO; 2013.

4. Rutherfurd SM, Darragh AJ, Hendriks WH, et al. True ileal AA digestibility of goat and cow milk infant formulas. J Dairy Sci 2006;89: 2408-13.

5. Bouzerzour K, Morgan F, Cuinet I, et al. In vivo digestion of infant formula in piglets: protein digestion kinetics and release of bioactive peptides. Br J Nutr 2012;108:2105-14.

6. Inglingstad RA, Devold TG, Eriksen EK, et al. Comparison of the digestion of caseins and whey proteins in equine, bovine, caprine and human milks by human gastrointestinal enzymes. Dairy Sci Technol 2010;90:549-63.

7. Almaas H, Cases A-L, Devold TG, et al. In vitro digestion of bovine and caprine milk by human gastric and duodenal enzymes. Internat Dairy $J$ 2006;16:961-8.

8. Ménard O, Gattenoz T, Guillemin H, et al. Validation of a new in vitro dynamic system to simulate infant digestion. Food Chem 2014;145: 1039-45.

9. Fondaco D, AlHasawi F, Lan Y, et al. Biophysical aspects of lipid digestion in human breast milk and Similac infant formulas. Food Biophysics 2015;10:282-91.

10. Havenaar R, de Jong A, Koenen MJ, et al. Digestibility of transglutaminase cross-linked caseinate versus native caseinate in an in vitro multi-compartmental model simulating young child and adult gastrointestinal conditions. J Agric Food Chem 2013;61:7636-44.

11. Havenaar R, Maathuis A, de Jong A, et al. Herring roe protein had a high digestible indispensable amino acid score (DIAAS) using a dynamic in vitro gastrointestinal model. Nutr Res 2016;36:798-807.

12. Bellmann S, Lelieveld J, Gorissen T, et al. Development of an advanced in vitro model and its evaluation versus human gastric physiology. Food Res Internat 2016;88:191-8.
13. Havenaar R, Anneveld B, Hanff LM, et al. In vitro gastrointestinal model (TIM) with predictive power, even for infants and children? Internat J Pharm 2013;457:327-32.

14. Schaafsma G. The Protein Digestibility-Corrected Amino Acid Score (PDCAAS). A concept for describing protein quality in foods and food ingredients: a critical review. J AOAC Internat 2005;88:988-94.

15. Bowles A, Keane J, Ernest T, et al. Specific aspects of gastrointestinal transit in children for drug delivery design. Int J Pharm 2010;395: 37-43.

16. Mooij MG, de Koning BAE, Huijsman ML, et al. Oncogeny of oral drug absorption processes in children. Expert Opin Drug Metab Toxicol 2012;8:1293-303.

17. Nguyen TTP, Bhandari B, Cichero J, et al. A comprehensive review on in vitro digestion of infant formula. Food Res Int 2015;76: $373-86$.

18. Rutherfurd SM, Moughan PJ, Lowry D, et al. Amino acid composition determined using multiple hydrolysis times for three goat milk formulations. Int J Food Sci Nutr 2008;59:679-90.

19. Darragh AJ, Moughan PJ. The amino acid composition of human milk corrected for amino acid digestibility. Br J Nutr 1998;80:25-34.

20. Silvestre D, Ferrer E, Gayá J, et al. Available lysine content in human milk: Stability during manipulation prior to ingestion. Biofactors 2006;26:71-9.

21. Koletzka B, Baker S, Cleghorn G, et al. Global standard for the composition of infant formula: recommendations of the ESPGHAN coordinated international expert group. J Pediatric Gastroenterol Nutr 2005;41:584-99.

22. Lönnerdal B. Nutritional and physiologic significance of human milk proteins. Am J Clin Nutr 2003;77(suppl):1537S-43S.

23. Prosser CG, McLaren RD, Frost D, et al. Composition of the non-protein nitrogen fraction of goat whole milk powder and goat milk-based infant and follow-on formulae. Int J Food Sci Nutr 2008;59:123-33.

24. Mahé S, Roos N, Benamouzig R, et al. True exogenous and endogenous nitrogen fractions in the human jejunum after ingestion of small amounts of ${ }^{15} \mathrm{~N}$ labeled casein. J Nutr 1994;124:548-55.

25. Park YW, Juárez M, Ramos M, et al. Physico-chemical characteristics of goat and sheep milk. Small Ruminant Res 2007;68:88-113.

26. Park W. Goat milk-chemistry and nutrition. In: Park YW, Haenlein GFW, eds. Handbook of Milk of Non-bovine Mammals. Oxford, UK: Blackwell Publishing; 2006:34-58.

27. Locatelli I, Kovacic N, Mrhar A, et al. Gastric emptying of nondisintegrating solid drug delivery systems in fasted state. Review Expert Opin Drug Deliv 2010;7:967-76.

28. Staelens S, Van Den Driessche M, Barclay D, et al. Gastric emptying in healthy newborns fed an intact protein formula, a partially and an extensively hydrolysed formula. Clin Nutr 2008;27:264-8. 